\title{
Tourism Development as a Strategy in Regional Planning
}

\author{
O. A. Ajala (PhD)
}

\section{Introduction}

Many strategies have been formulated and applied in regional development since the second half of last century, by scholars and governments in various parts of the World, particularly in the Less Developed Countries (LDCs). The success and failure of different strategies has been at varying degrees and dimensions from one country to the other.

Some of these strategies had focused on industrialization, exploration of mineral resources, and exportation of primary products and concentration of investments in the major urban centres at the expense of the regions. the basic theory underpinning these types of development strategies is the "Growth pole theory" developed by Perroux (1950) which was modified by the works of Myrdal (1957), Hirschmann (1958) and Bouldeville (1966) as "Growth Centre Theory".

The inability of the growth centre models to bring about the desired equitable balance development and the increasing disparity in the level of development helped to fuel the search for alternative paradigm for development. In the past three decades, scholars came up with the "Bottom-up Theory" of regional development as opposed to the growth centre model which is regarded as Centre -down approach". The bottom-up approach came with several strategies such as -modernization approach; basic needs strategy; integrated rural development approach; agro-politan strategy and agribusiness approach, to a mention a few (see Adeyinka et 
al 2002). These various strategies of bottom-up paradigm tend to focus on individual elements of development at the regional levels.

According to World Bank (1975), regional development is a process of growth, transformation and progress. The growth is manifest able in retaining and absorbing youthful progressive and productive population. It also implies restructuring of economy in order to satisfy the material needs and aspiration of the people, particularly the rural masses that constitutes a larger proportion of the population. it must, in addition promote individual and collective incentives to participate in the process of development. The "progress" content of regional development is the transformation of the monotonous and stagnating condition of people in the countryside to a dynamic and exciting one.

In the word of Lele (1979), development is defined as improving living standards of the mass of the low-income population residing in the rural areas and making the process of their development self-sustaining. According to her, this simple definition has three important features with substantial implications for how regional development programmes are designed and implemented; namely-

1. Improving the living standard of the subsistence population involves mobilization and creating conducive environment for the people to increase their income generation capabilities,

2. Mass participation requires that people are involved in the formulation and design process of developmental programmes, and

3. Self-sustenance thus means involving the people in the implementation and management of development programmes with the ultimate goal of improving the economic and social life of the people. 
Given the above scenario, regional development a holistic approach in order to fulfill these three features as listed above, various government in the LDCs have used sectoral approach to regional development with focus on different aspects of the economy. A neglected sector of the economy by many LDCs in the world and particularly subSahara Africa is tourism. According to Cole (1981) development is dependent on the level of natural resources endowment and level of technology of a nation among others. Many less developed Countries did not realized tourism resources in their country as endowment with potential of rapid socio-economic development, capable of generating foreign exchange, reducing unemployment and improving the standard of living of the people.

This paper thus, examines different features of tourism resources and its adaptation as a strategy in regional planning. The paper is divided into sections. Immediately after the introduction, is the definition, potentials and benefits of tourism; followed by the treasures for tourism development; eco-tourism as an approach to tourism development; criteria for eco-tourism development; some examples from Nigeria; eco- tourism treasures in Amhara region of Ethiopia and conclusion.

\section{Tourism: -Definition, Potentials and Benefits}

Tourism is defined as leisure industry "which operates within capabilities for regeneration and future productivity of natural resources; recognizes the contribution of people and communities, costumes and lifestyles to the tourism experience; accept that these people must have equitable share in the economic benefits of tourism and guided by the wishes of the local people and communities in the host 
area" (WTTO and IHRA, 1999). Tourism environment therefore comprises of physical and human components. The physical component includes- landscape scenery, weather and climate, water and natural biodiversity of plants and animals; while the human component encompasses history, culture and tradition of the people, all these provide challenges and adventures for people.

Tourism has become an appealing sustainable economic development strategy for the Less Developed Countries in dire need of alternative source of foreign exchange earnings. Next to oil, tourism is the net foreign exchange earner at the international level. It is the highest employer of labour in the tertiary sector of the World economy and the second largest after agriculture. Tourism potential impact on the economy cut across several sectors to include- transportation, manufacturing, food processing and packaging, construction, trade and commerce and other ancillary services. It is an international commodity, thus it has a global market from where it draws its patronage and there is no age barrier for its customers.

United Nations Environmental Programme (UNEP, 2000) identified a number of benefits of tourism. Some of which include the following:

- Generation of foreign exchange and income for government and individuals,

- Generation of direct and indirect employment opportunities with greater multiplier effects,

- Encourage peoples participation at all levels,

- It engender the development of public infrastructures (transport, electricity, water and health), 
- It contributes significantly to environmental protection, the conservation and restoration of biological diversity (plants and animals) and sustainable use of natural resources, and

- It has the potential to increase public appreciation of the environment and to spread awareness of environmental problems when it brings people into closer contact with nature. This confrontation may heighten awareness of the value of nature and lead to environmentally conscious behaviour and activities to preserve the fragile environment.

\section{The Treasure for Tourism Development}

There is no location on the earth's surface that does not possess one thing or the other to attract tourists. What makes the difference is the way tourist facilities are packaged for both local and international consumption. Admittedly, there are urban recreational centers and resorts, yet the largest tourist potentials are found in the countryside of any nation. Treasure for tourism development falls into three categories:

1. Natural treasures include - geological or topographic features of particular interest, rare plants, animals water bodies (Ocean, Seas, lakes and waterfalls) and ecological features deemed worthy of preservation and areas of special scenic appeals,

2. Man-made treasures such as prehistoric sites (camp, artworks etc), ancient monuments (precious stones, monoliths, historical buildings and ruins, and memorials), and features of industrial archaeological interest, and 
3. Allusive treasures include those places that possess historic, biographical, artistic and literary, culture, tradition and lifestyles of the people.

All these constitute part of natural heritage of all nations in the World, most of which are located in the countryside and provide great attraction, challenges and adventures to both local and international tourists.

The demand and uses of tourism facilities can also be grouped in to five as:

1. The desire for quiet space and the peace of nature by short holidaymakers for the refreshments of body and mind. The pressures of modern life, which can be assuaged by tranquility, necessitate the rest and recuperation for an escape from crowd, a return to sanity and to quiet environment for rejuvenation.

2. Taking in the unpolluted view of natural environment by traveling to distant places in countryside and finding content and relaxation in the exercise.

3. Taking outdoor activities that are permissible in the countryside such as hunting, shooting, fishing, sailing or canoeing, swimming, mountain climbing etc. These are mainly rural environment sporting activities whose facilities can be both natural and artificial on which people are prepared to spend their leisure and extra disposable income.

4. Educational use- tourist facilities possess dual characteristics as a tool for researchers and as well as object of research on its own, and

5. The use of countryside for "second home" permanently or temporarily with country home cottages as apart. 


\section{Eco-Tourism as an approach to Tourism Development}

The concept of "eco-tourism" developed a few decades ago gave a new impetus to the adaptation of tourism as a strategy in regional planning and development, with a noticeable multiplier effect. Eco-tourism is a holistic approach to tourism development because it integrated the three basic goals of development within its operation these are economic goals, social goals and environmental goals, as illustrated in figure 1.

Figure 1 Integrated Goals of Eco-Tourism.

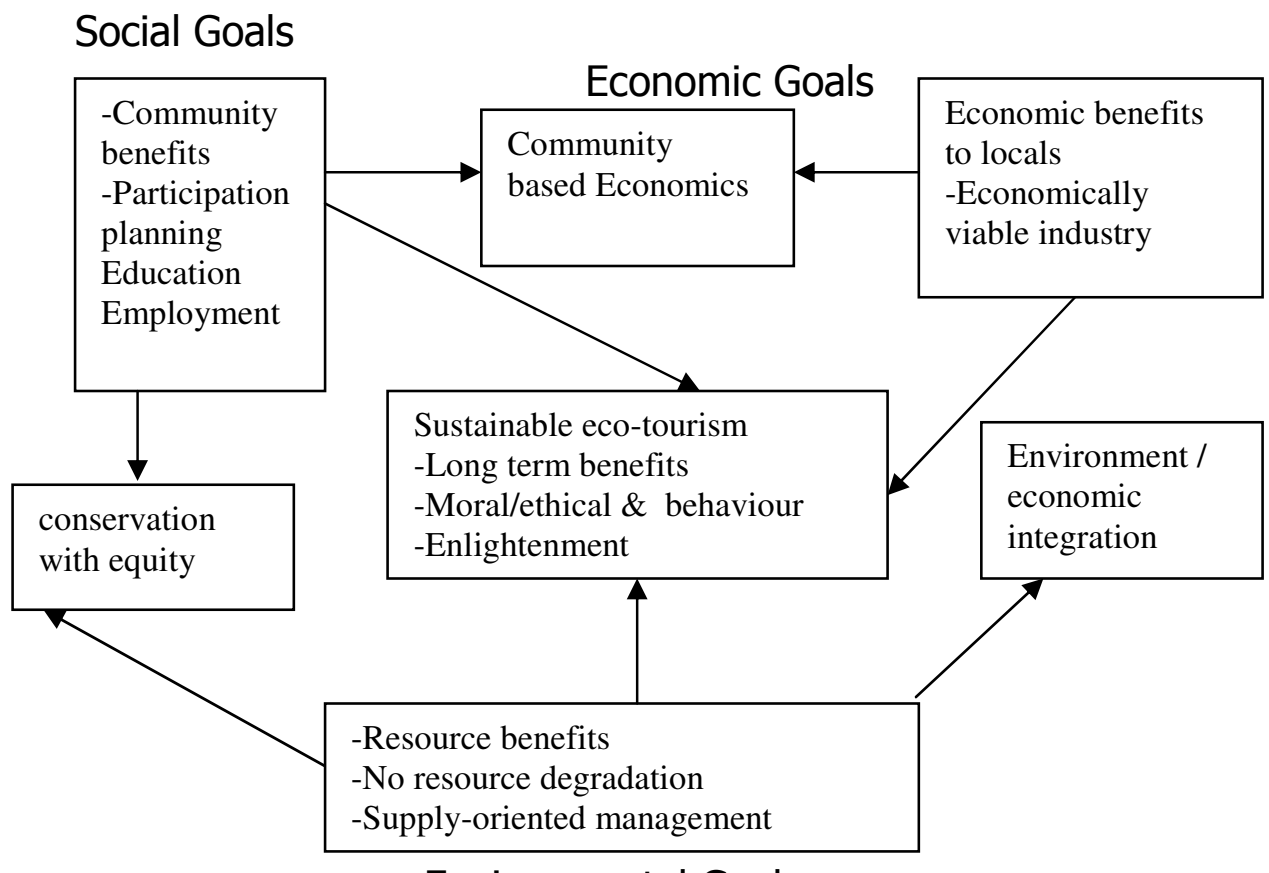

Environmental Goals 
Eco-tourism aims at introducing the environment as a resource for tourism and recreation and outline management techniques. It is of special interest for its relationship with conservation, sustainability, and biological diversity. As a development tool, eco-tourism can advance the following three basic goals, which are:

> Conserve biological (and cultural) diversity, by strengthening protected area management systems (public or private) and increasing the value of sound ecosystems

$>$ Promote the sustainable use of bio-diversity by generating income, jobs and business opportunities in eco-tourism and related business networks

$>$ Share the benefits of eco-tourism developments equitably with local communities and indigenous people, by obtaining their informed consent and full participation in planning and management of ecotourism businesses

Eco-tourism introduces new leisure resources based economies, examines adverse environmental and cultural impacts and outlines methods of managing recreational pressures on the environment.

Eco-tourism encompasses the following five criteria:

1. Conservation: conservation may be practiced in the form of private reserves, native tree reforestation, or supporting established reserve areas. Although protected areas are extremely attractive for tourists to visit, it is important to know that the purpose of a protected area is to maintain habitat for flora and fauna, allowing species to exist and thrive without human 
interference. Whenever visiting a protected area, the visit should be made with minimal impact.

2. Low Impact And Green Efforts: the concept of 'green hotels' popularly known as 'Ecotels' is in vogue where ecological management practices such as recycling of water, composting and energy conservation are followed.

3. Sustainability: sustainability means a lifestyle that is in balance, and can easily be maintained in the future. This is especially important when visiting ecologically sensitive areas. Good examples of sustainability are construction using local materials and methods and organic gardens for food production.

4. Community Involvement: community Involvement is one of the most important parts of eco-tourism. Considerations taken into account include whether tourism is helping the area and if the establishment is sensitive to its effect on the community. Tourism needs to benefit the local population and culture. Ideally, the community should own the establishment, but if this is not so, the locals that are employed should have nonmenial jobs. The community should profit from the resources that they are willing to share with visitors.

5. Environmental Education And Interpretation: environmental education and interpretation means that as a guest one leaves as Eco- facility having learned something about the environment, the culture, or even new ways of recycling. It is important that the spread of information is clear and relevant. Educational programmes that help 
the community to preserve their environment and advance themselves also play a very crucial role.

\section{Sustainable Tourism Development}

As with other land and water resources, tourism and recreation should be sustainable. Long-term integrity of ecosystems and preservation of the regenerative capacity of the environment (that is sustainable development) requires linking of ecological principles to economic processes to reduce environmental stress as well as meeting the needs of the populace.

The concept of sustainable tourism varies from one nation to the other but remains a developmental strategy for tourism development. However, it does not reduce the availability of natural capital and does not deny visitors the opportunity to enjoy the same experience. Three variables make up sustainable tourism namely ecological, socio-cultural and economic sustain abilities. According to Puczko (1998) ecological sustainability ensures that the development is compatible with the site's environmental process while economic sustainability emphasizes continuous benefit for all generations and socio-cultural variable makes sure that tourism development retains community identity. Thus, eco tourism falls within the purview of the concept of sustainable development and it is relevant to tourism developments. In many areas of developing countries of the World traditional cultures and wilderness environments are under pressure from population growth, resource exploitation, poor management (internal development pressures) debt, and recreation development problems (external development pressures).

The environment has a limited capacity to absorb impact from human use and still retain the qualities, which made it attractive to tourism and recreation in the first place. 
As use increases or damaging patterns of use develop, the environmental quality deteriorates. Carrying capacity is a key concept in management of tourism and recreation. It is the use an area can tolerate with out unacceptable change and provides a framework to preserve environmental quality. Two important parameters may be applied to managing tourism and recreation:

a. Biophysical carrying capacity is the amount and type of use an environment can sustain without undue evidence of unnatural impact or overuse. De-vegetation of frequently used areas( for example, campsites, picnic areas, viewpoints), proliferation of trails and soil erosion, disturbance of wildlife and excessive litter indicate if biophysical carrying capacity is being approached or exceeded

b. Socio-psychological carrying capacity is the level of humans using an area that can accommodate before experiential values are diminished. Concentration of visitors in popular areas, overcrowded campsites, and hotels and crowded trails and places of interest, indicate if social carrying capacity is being approached or exceeded

Carrying capacity is relative and not an absolute figure. It is a subjective measure of environmental value and the characteristics of the area in question and can only be established by judgmental decisions. The definition of capacity limits must be part of any management plan, if unacceptable impacts are to be avoided.

Thus eco-tourism is sustainable when it: 
- Ensures prior informed participation of all stakeholders

- Ensures equal, effective and active participation of all stakeholders

- Acknowledges indigenous peoples / communities' rights to say 'no' to tourism development-and to be fully informed of effective and active participation in the development of tourist activities within the communities, lands, and territories

- Promotes process for indigenous peoples and local communities to control and maintain their resources

The Quebec declaration has recognized that eco-tourism 'embraces the principles of sustainable tourism'. However, the declaration has also identified the following specific principles, which distinguish it from the wider concept of sustainable tourism:

- Contributes activity to the conservation of natural and cultural heritage. Include local and indigenous communities in its planning, development and operation, contributing to their well being

- Interprets the natural and cultural heritages of the destination to visitor

- Lends itself better to independent travelers, as well as to organized tourism for small size groups.

Eco-tourism as a concept in sustainable development should be applied to all these forms of tourism to include sport, health, beach, culture and adventure. If the principles of sustainability are applied, then the type of tourism can be called sustainable tourism therefore it can apply to all tourism activities. For eco-tourism to be successful it must promote sustainable development by establishing a durable productive base that allows local inhabitants and service base that allows local inhabitants and service provides to enjoy rising 
standards of living. Eco-tourism must incorporate the social dimensions of productive organization and environmental conservation. Unless eco-tourism activity incorporates the local society into service planning and provision, and includes programmes to meet the fundamental needs for income and employment for all people in the region, the special qualities of the site and its flora and fauna may be irreparably damaged.

Effective management of eco-tourism can be realized by incorporating the following aspects as suggested by the USAID

- Identification and mobilization of funds for potential private nature tourism investments

- Formulation of fiscal policies such as visitor fees, regulations for tourism operations, investment incentives and land use zones for tourist and to maximize its economic and environmental benefits

- Formulation of public policies that promote environmentally sound tourism as well as community involvement in providing services and products such as guides, lodging, transport, and crafts

- Encouragement of international exchange of information and know -how about by nature tourism opportunities and operations through technical and management training, to meet the needs and interests of international and domestic nature tourists

- Monitoring and certifying the performance of ecotourism activities to promote environmentally responsible tourist operations that conserve energy, recycle waste, and instruct staff and tourists on proper behavior in parks and protected areas 
- Funding research on eco-tourism developmental and environmental impact

\section{Tourism Development- Nigeria Experience}

There is several natural tourist attraction sites scattered all over the country. The diverse climatic zones with its biodiversity, topography, coastline, diverse culture and traditions provided the opportunity for tourism development in Nigeria. Little attention was paid to tourism in the past; however, there have been rapid tourism development within the last decade, with policy changes that attract private investors into tourism business. There is along list of examples that can be considered, but only two is considered in this paper to illustrate how tourism development has been used as a strategy for socio- economic development in regional planning. The two examples are Eleko Beach Resort in Lagos and MIC-COM Golf Country Resort, Ada, Osun State.

\section{A Eleko Beach Resort in Lagos}

Eleko is a sand barrier coastal village in Lekki peninisular, Lagos Southwestern Nigeria. It has a population of 5000 people as at 1991(NPC1997). It is 75 kilometers from metropolitan Lagos and fronts Atlantic Ocean on Longitude $13^{0}$ degree East of the Greenwich Meridian and Latitude $4^{0}$ degree North of the Equator. The village runs linearly along the 150 meters recommended set back starting from the landward base of primary sand dune line. The golden sandy beach and 30 nautical miles Atlantic continental shelf constitute the natural capital of the community.

Eleko village is encumbered with serious economic and environmental challenges such as pollution of Lagoon, destructive fishing practices that has drastically reduced the 
aquatic stocks, unemployment and poverty leading to out migration of the productive labour force to metropolitan Lagos. The completion of Lekki- Ibeju coastal road in 1988 exposed the scenic beach landscape to tourists and marked the beginning of tourism development in the community.

Eleko Seaside Club was the premier social organization that triggered the beach development in 1990. It was an informal village club with a beach cabin clubhouse overlooking the ocean, which also served as landing spot for fishermen operating on the continental shelf. The sudden increase in number of tourists to the beach draw the attention of the traditional council of the village; he encouraged each household in the village to build beach cabin on the community land without destroying the coconut plantation owned by individuals along the shore line. They also encouraged the husbands to build foodservices stalls behind the tourists' cabins for their wives. In 1991 Eleko Community Development Association (CDA) was formed to coordinate socio-economic development of the village with supervisory role by Lagos state community development organization office of Ministry of Local Government and Chieftaincy Affairs. The CDA constitute the community stakeholders in the beach tourism project and represent the political voice of the village.

With the beach tourism development in Eleko village the socio-economic situation of the village has changed as about 90 percent of the community members currently derived their means of livelihood from tourism services as employees in the tourist cabins, food vendors, boat drivers, cultural dancers and Horse riders. In recent time those that have migrated out have started returning back to the village while tourist investor have also moved into the village to 
establish other tourist facilities which the community can not provide by themselves (Adejumo, 2003; 2005)

\section{B. MIC-COM Golf Country Resort, Ada, Osun State.}

MIC-COM Golf Country Resort, is a privately owned, Golf country resort situated on about 100 hectare of Land in Ada, Boripe Local Government Area of Osun State. The State is located within latitudes $6^{0} 55^{1}$ and $8^{0} 10^{1}$ North and longitudes $3^{0} 55^{1}$ and $5^{0} 05^{1}$ East of South Western Nigeria. It covers a total landmass of about 7997.5484 square kilometers with an estimated population of $2,854,832$ in 2001 (NPC 1997).

Ada community is a typical rural community with a small population of about 20,000 as at 1991 , the people are predominantly farmers and they also engaged in local craft. The settlement is specially noted for the production of local soap making. The topography of the area, which is 12001500 , above mean sea level and relatively plain provided a good terrain for the Golf course, which the major sport tourism activity developed in the area.

MIC-COM Golf resort is multi purpose resort center providing several tourism services. Apart from the golf course there is the hotel facility providing accommodation and other related services to Golfers and other tourists visiting the resort. It also offers conference services with a number of large Conference halls and Workshops/Seminar Rooms.

With the level of the development in this resort center it now became the center of attraction to government at both state and national level. The resort now host many government functions such as retreats and training programmes for civil servants. Also professional associations and companies are using the resort facilities for their annual conferences and general meetings. 
The presence of this resort center in a formerly remote, rural and less developed town in the state has brought a lot of recent development to the town. The State and Local Governments rehabilitated the road leading to the town of which many other towns along the route also benefited. Two, there is increased patronage of people's local craft and other cultural artifacts; the resort center also provide more than 300 direct employment to the indigenes and un-estimated indirect employment to the inhabitants. All this had changed the fortune of the community for better, their living standard socio-economic lives improved tremendously and the beauty of the natural environment is preserved.

\section{Observation of the Situation in Amhara Region, Ethiopia}

The abundance and diversified natural environment in Ethiopia and particularly Amhara region, coupled with a rich history, culture and tradition of the people in Ethiopia provided the necessary ingredients for the exploitation of tourism potentials as an alternative source of foreign exchange for the government and as well to contribute significantly to the socio-economic development in Amhara region. However, the presence of several natural and man made Tourist attraction Sites in Amhara region that include Lake Tana, Monasteries, waterfall, wildlife, Ancient Churches etc. has not translated to a meaningful socio-economic development in the region due to under utilization/ underdevelopment of the Tourism potentials. Unemployment rate is very high and rate of poverty is becoming endemic not only in Amhara region but a large proportion of Ethiopian population are living below the poverty line with many earning less than \$1US Dollar per day (ANRS,2003). 


\section{Conclusion}

Given, the Nigeria experience by the few examples, it could be acclaim that tourism development has the potentials to bring about rapid development to regions that are lagging behind. When the right circumstances (such as natural tourist sites, market feasibility, management capacity at local level, and clear and monitored links between eco-tourism development and conservation) are present, well-planned and managed, eco-tourism development has proven to be one of the most effective tools in development planning at regional level for its tripartite social, economic and environmental gains. Thus, if tourism is a tool for economic development, then carrying capacity is the compass and eco-tourism is the route map for sustaining the economic development. The fortune of Amhara region and other parts of Ethiopia can be transformed if tourism development is adopted as a regional planning strategy, which is capable of providing jobs for thousands of people and greatly reduce the level of poverty in Amhara region and Ethiopia at large.

\section{References}

Adejumo 0.T. (2003) Development strategy for Sustainable Public Park system in Metropolitan Lagos- in The city in Nigeria OAU Press,Ile-Ife. pp112-120

Adejumo 0.T. (2005) Sustainable Beach Tourism:

Formalization of Local Agenda For Eleko Community Coastal Resources. In Fadare et al (edit.) Globalization, Culture and The Built Environment-National Conference Proceedings by Faculty of Environmental Design and Management. Obafemi Awolowo University, Ile-Ife, Nigeria pp 322-329 
Adeyinka S.A. Ajala O.A. and Sanni L. (2002) Process of Rural Development: A Theoretical and Empirical Analysis of Alternative Methods-in Ibitoye O.A. (edit.) Rural Environment and sustainable Development in Nigeria. Pp 32-38

ANRS (2003) Development Indicators of Amhara Region. Amhara National Regional State(ANRS), Bureau of Finance and Economic Development, Bahir Dar.

Boudeville J.R. (1966) Problems of Regional Economic Planning, Edinburgh University Press, Edinburgh.

Brass J. (1997) "Community tourism Assessment Hand Book". Western Rural Development Centre, Logan, USA

Hirschmann, A.0.(1958). The strategy of economic development. Yale university press,

Ishida L. (1999) "Eco-tourism through participatory action research : A case study of a community based project in Hugotulco, Mexico." Michigan State University, USA.

Kurian Joseph and R.Nagendran (2005) Essentials of Environmental Studies. Pearson Education, Singapore

Lele U. (1979) The Design of Rural Development, Lessons from Africa. Baltimore Johns Hopkins University.

Myrdal G. (1957) Economic theory in under developed regions Gerald Duckworth, London.

N.P.C. (1997) Census' 91 National Summary. National Population Commission.

NTDC (2002) Nigeria: Beauty in Diversity a handbook on Nigeria Tourism. Nigeria Tourism Development Corporation, Abuja Nigeria

Puczko L.R. (1998) "Rural Tourism and Sustainable Development" International conference on the Rural Tourism management, Scotland. 
Renard Y. (2001) " Practical Strategies for Pro-Poor Tourism: A case study of the St. Lucia Heritage Tourism Programme" PPT Working Paper No. 7 http://www.pro-poortourism.org.uk

Samson B.F and F.L. Knoff (1996) Ecosystem Management. Springer-Verlag New York.

Tanimowo N.B. (2002) Tourism for Rural Development in Nigeria--. in Ibitoye O.A.(edit.) Rural Environment and sustainable Development in Nigeria . Pp 62-64

World Bank (1975) Rural Development Sectoral Policy, Policy paper on rural enterprise and non-farm employment, World Bank, Washington D.C.

Whittaker R.H. (1975) Communities and Ecosystem 2nd ed. Macmillan New York

WTO (2001) World Tourism Organization Annual Report,World Tourism Organization, Barcelona, Spain

WTTO \& IHRA (1999) " Tourism and sustainable Development: The Global Importance of Tourism" Background Paper 1 Prepared by World Travel and Tourism Organization and International Hotel and Restaurant Association Commission on Sustainable Development.

WTTC, WTO, \& EC (1997) "Agenda 21 for the travel and Tourism Industry: Towards Environmentally Sustainable Development" Presented at the 1997 United Nations General Assembly. World Travel and Tourism Council, London, World Tourism Organization, Madrid and Earth Council San Jose. 